\title{
Las intervenciones críticas de Roberto Bolaño: el escritor como estratega en el combate literario
}

The Critical Interventions of Roberto Bolaño: the

Writer as a Strategist in the Literary Battle

As intervenções críticas de Roberto Bolaño: o escritor

como estrategista na luta literária

\section{Rafael Gutiérrez Giraldo}

UNIVERSIDADE FEDERAL DO RIO DE JANEIRO, BRASIL

Investigador de posdoctorado, Departamento de Letras Modernas, Área de

Literatura Hispanoamericana, Universidad de São Paulo. Doctor en

Estudios de Literatura, Pontifícia Universidade Católica do Rio de Janeiro

(PUC-Rio). Ha publicado El escritor de culto. Guía rápida (Editorial

Universidad de Antioquia, Medellín, 2013) y Diálogos literários entre

o Brasil e a América Hispánica como organizador (Editorial 7 Letras, 2010). Correo electrónico: rafaelgutierrezgiraldo@yahoo.com.br

El presente artículo hace parte del proyecto de posdoctorado que realizó el autor en la Universidad de São Paulo sobre las relaciones entre crítica y ficción en la literatura latino-americana contemporánea con apoyo de la Fundação de Amparo à Pesquisa do Estado de São Paulo (FAPESP).

Documento accesible en línea desde la siguiente dirección: http://revistas.javeriana.edu.co 


\section{Resumen}

El presente texto busca describir y analizar las principales características de las intervenciones críticas del escritor chileno Roberto Bolaño. Tanto las intervenciones correspondientes a su etapa del movimento infrarrealista, durante los años 70 en México, como las realizadas durante la etapa final de su vida cuando era considerado un escritor consagrado, entre 1998 y el año de su muerte, 2003. El texto analiza las estrategias discursivas de sus intervenciones, sus principales objetos de interés y las formas en que el autor construye su propio mito de escritor.

Palabras clave: crítica de los escritores; crítica y ficción; Roberto Bolaño; América Latina

\section{Abstract}

This article describes and analyses the main characteristics of Chilean writer Roberto Bolaño's critical interventions. It takes into account the interventions in the context of the Infrarrealist Movement, during the 70's in México, and those of his life's final period, between 1998 and 2003, when he reached the status of acclaimed writer. The article analyses the discursive strategies of these interventions, their main topics and the ways through which the author constructs his own writer myth. Keywords: critique and fiction; Roberto Bolaño; writer's critique; Latin America

\section{Resumo}

O presente texto visa descrever e analisar as principais características das intervenções críticas do escritor chileno Roberto Bolaño. Tanto as intervenções correspondentes a sua fase do movimento infrarrealista, durante os anos 70 no México, quanto aquelas realizadas durante a etapa final da sua vida quando foi considerado um escritor de renome, entre 1998 e o ano da sua morte, 2003. O texto analisa as estratégias discursivas das suas intervenções, seus principais objetos de interesse e as formas que o autor constrói seu próprio mito de escritor.

Palavras-chave: crítica dos escritores; crítica e ficção; Roberto Bolaño; América Latina

RECIBIDO: 12 DE DICIEMBRE DE 2013. APROBADO: 24 DE ENERO DE 2014. DISPONIBLE EN LÍNEA: 30 DE JULIO DE 2014.

Cómo citar este artículo:

Gutiérrez Giraldo, Rafael. "Las intervenciones críticas de Roberto Bolaño: el escritor como estratega en el combate literario". Cuadernos de Literatura 18.36 (2014): 310-331.http://dx.doi.org/10.11144/Javeriana.CL18-36.icrb 
"Si uno se toma en serio una cosa, o todas, de las que dice un escritor, es inevitable que lo malentienda y no pueda tomárselo en serio en bloque"

CÉSAR AIRA

A LO LARGO de su trayectoria como escritor Bolaño practicó una gran variedad de intervenciones críticas: manifiestos, artículos, prólogos, discursos, diálogos con otros escritores, entrevistas. Esas intervenciones se enmarcan en dos momentos específicos separados ampliamente en el tiempo: los años del movimiento infrarrealista en el México de mediados de los años 70 y el periodo de su consagración como escritor a partir de 1998 hasta el año de su muerte, 2003.

A pesar de esta diferencia de etapas, de manera general las intervenciones de Bolaño conservan ciertas características comunes como el humor y el tono provocador y polémico, y un cierto tipo de escritura que no se preocupa demasiado por las diferencias entre géneros críticos y ficcionales, lo que hace difícil llegar a definiciones cerradas sobre el carácter de estos textos situados entre la crítica, el panfleto, el ensayo, la ficción y una especie de autobiografía de lecturas.

En este artículo voy a analizar de manera muy breve las intervenciones correspondientes a la primera etapa infrarrealista de Bolaño solamente como antecedentes para situar y entender el estilo y los objetivos de sus intervenciones posteriores como escritor consagrado, las cuales están constituidas por el mayor volumen de sus textos críticos así como, en general, por los más conocidos.

\section{Los primeros textos, el gesto vanguardista}

Quizás poco exploradas en la primera oleada de recepción crítica de la obra de Bolaño, paulatinamente las cuestiones relativas a su participación y sus publicaciones en torno del movimiento infrarrealista en México a mediados de los años 70 comienzan a ser más investigadas y discutidas ${ }^{1}$. Ignacio Echavarría, por ejemplo, decide no incluir en la organización de Entre paréntesis estos textos tempranos de Bolaño, según él para "no romper la notable sintonía de todos los materiales" que componen el libro, es decir los textos publicados por Bolaño a partir de 1998 (15). El propio Bolaño hace pocas referencias a su paso por el infrarrealismo en sus entrevistas o textos de corte más autobiográfico, aunque es evidente que una novela como Los detectives salvajes está construida precisamente sobre esta experiencia y que la figura del poeta rebelde de vanguardia es central en toda su obra ficcional.

1 Véase por ejemplo Campo; Cobas Carral; Espinosa; García Huidobro. 
Corresponden a esta primera etapa el "Primer manifiesto infrarrealista. Déjenlo todo nuevamente", publicado en la revista del movimiento, Correspondencia Infra, de octubre-noviembre de 1977; los artículos publicados en la revista Plural: "El estridentismo" (1976), "Tres estridentistas" (1976) y "La nueva poesía latinoamericana (crisis o renacimiento)" (1977); y en un orden distinto pero en relación con esta etapa, su papel como organizador de una antología de poesía infrarrealista titulada Muchachos desnudos bajo el arcoíris de fuego (1979).

Este primer conjunto de artículos críticos de Bolaño está enmarcado en un gesto vanguardista en cuanto crítica radical al orden existente y búsqueda de reintegración del arte en la vida (pienso en el caso específico del manifiesto infrarrealista, pero también en el lenguaje y argumentos de su artículo sobre la nueva poesía latinoamericana), y marca el origen de la actitud rebelde e irónica que vamos a encontrar en sus textos críticos posteriores ${ }^{2}$.

En la búsqueda del joven escritor de unos posibles maestros y modelos para seguir, Bolaño no apunta su mirada hacia autores que desde los años 30 habían comenzado a realizar una renovación narrativa en América Latina (como Arlt, Onetti o Rulfo) ni a poetas consagrados e innovadores como Nicanor Parra o Neruda. Tampoco hacia los autores que en ese momento protagonizaban el llamado boom latinoamericano (García Márquez, Carlos Fuentes, Vargas Llosa, Cortázar), ni hacia la figura central del mundo literario mexicano del momento: Octavio Paz, aunque este último aparece como el blanco predilecto de los ataques de los infrarrealistas. Bolaño elige, en cambio, recuperar la vanguardia de inicios del siglo XX, tanto la vanguardia histórica europea, con sus guiños evidentes al surrealismo, como la latinoamericana de los años 20, volviendo su atención y señalando como maestros a los autores del estridentismo mexicano y declarando como sus pares literarios a movimientos latinoamericanos considerados por Bolaño vanguardistas, como Hora Zero del Perú, los tzánticos ecuatorianos y los nadaístas de Colombia.

Los artículos de Plural están dedicados a recuperar el estridentismo a través de una breve presentación y reproducción del "Manifiesto estridentista" de 1923 y de entrevistas a sus tres principales exponentes: Maples Arce, Arqueles Vela y List Arzubide.

El manifiesto infrarrealista redactado por Bolaño comparte el lenguaje, algunos juegos tipográficos (como los espacios en blanco, el uso de caracteres

2 No es mi intención aquí discutir el propio concepto de vanguardia o neovanguardia y su pertinencia en relación con movimientos latinoamericanos como el infrarrealismo. Ana Longoni, por ejemplo, analiza lo problemático del uso de una definición estricta de vanguardia como la planteada por Peter Bürger para el contexto latinoamericano. 
en mayúscula, la ausencia de signos ortográficos), las proclamas combativas revolucionarias y el tono humorístico de los típicos manifiestos vanguardistas de inicios de siglo XX. Como afirma Jorge Schwartz: "La vanguardia substituye la 'seriedad' académica y normativa por el 'humor', uno de los aspectos más importantes en todos los movimientos contestatarios" (73). El humor que caracteriza esta etapa de Bolaño se conserva en el resto de sus intervenciones críticas, como se verá más adelante.

El infrarrealismo propone como estrategia central de intervención del artista la conjunción arte-vida-política: "Nuestra ética es la revolución, nuestra estética la Vida: una-sola-cosa" (Bolaño, "Déjenlo todo" 3). Los infrarrealistas proponen "subvertir la realidad cotidiana de la poesía actual" y para hacerlo proponen desplazar el acto de escribir de sus lugares tradicionales hacia zonas que no sean las más propicias para la escritura (3). Esta idea, que aparece en sus primeras elaboraciones críticas sobre poesía, puede estar relacionada con la manera en que Bolaño coloca en sus ficciones posteriores a escritores y poetas en situaciones y lugares de peligro, en principio, poco propicios para la creación literaria. Esa relación arte-vida será también un argumento central para los criterios de valoración bolañianos tal como serán evidenciados en sus intervenciones posteriores.

El Bolaño de esta primera etapa es más radical en cuanto al reconocimiento y la valoración de la tradición literaria latinoamericana. Frente a los autores de la vanguardia de las primeras décadas del siglo XX, entre quienes menciona a los estridentistas, a Huidobro, a Borges, a Vallejo, a Girondo, lo que se escribe en los cuarentas y cincuentas "se ve definitivamente asqueroso" (Bolaño, "El estridentismo" 49). A partir de los años 6o, según Bolaño, la situación tendería a mejorar con movimientos como Hora Zero en el Perú y como los propios infrarrealistas que retoman el gesto de las vanguardias históricas. Estas primeras intervenciones del escritor como crítico dibujan el mapa de la literatura del momento de manera radical, señalando sin ambigüedades qué es lo que vale la pena rescatar del pasado y del presente, de forma que establecen su papel central como continuador de la única línea, según él, ética y estéticamente valiosa en la literatura latinoamericana.

Declaraciones de sus integrantes apuntan como objetivo del movimiento infrarrealista "volarle la tapa de los sesos a la cultura oficial" o "partirle su madre a Octavio Paz" (cit. en Cobas 1), en un gesto de rebelión frente a la cultura oficial y académica establecida. En estas primeras intervenciones, Bolaño identifica, por un lado, el aparato oficial de la literatura, el cual considera mediocre, y por el otro, un movimiento estética y éticamente al margen, que considera 
como el segundo cartucho de dinamita (las metáforas bélicas son características de la virulencia vanguardista y Bolaño no las abandonará nunca) de la poesía latinoamericana del siglo XX. El primer cartucho de dinamita sería el de la vanguardia de la segunda década del siglo, representada de manera ejemplar por los estridentistas mexicanos, a los que Bolaño elige como sus antecesores y a quienes les dedica estos primeros artículos, en un claro movimiento de recuperación de un canon particular que se erige como precursor.

El enfrentamiento se establece en este primer momento entre jóvenes decentes, de "cotidianidad de toilette", que buscan un "estatus" de escritor, y los jóvenes anarquistas, los poetas narrativos, los nuevos líricos marxistas, los que "viven poesía" y a los que no les importa el "oficio" de escritor. La obsesión de Bolaño, su lucha contra un tipo de escritor servicial, no escandalizador, no rebelde, se mantendrá, aunque con algunas connotaciones distintas, a lo largo de sus intervenciones críticas y también será un tema recurrente en sus novelas y relatos. Pero, como es lógico, la posición del joven vanguardista y rebelde radical se irá transformando con el tiempo. Aun cuando Bolaño intente mantener en parte el discurso contestatario que caracteriza estas primeras intervenciones, su postura política se hará menos radical así como su posición dentro del campo literario dejará de ser la posición marginal que caracteriza esta primera etapa.

La obsesión de Bolaño por las listas y las clasificaciones, técnica que utilizará también en sus obras ficcionales, puede ser encontrada desde estos primeros textos. Bolaño agrupa escritores, siguiendo con su metáfora bélica, como soldados en un campo de batalla. De un lado el escritor y sus amigos - porque obviamente él está incluido en el grupo privilegiado-y del otro los enemigos, los que escriben desde el "cubículo universitario", los hijos de Paz, etc. A la figura del escritor oficial y académico, habrá que añadirle en las intervenciones posteriores de Bolaño la del escritor de éxito de mercado o best-seller como figura central contra la cual debe combatir el "verdadero" escritor.

En este sentido, la confrontación le sirve para afirmar y evidenciar su propia visión de lo que debe ser la literatura. Para el Bolaño de este periodo y sus secuaces, la verdadera literatura debe ser una experiencia viva, lenguaje vivo, "el acto de escribir desesperadamente en un callejón sin salida" y de tener la capacidad de arriesgarse en mundos desconocidos; de ahí su insistencia, por ejemplo, en ver la literatura como un "oficio peligroso".

A pesar del poco impacto que pudo haber tenido efectivamente el movimiento infrarrealista, lo que me interesa destacar es que Bolaño evidencia desde el inicio de su actuación como escritor una fuerte voluntad de intervención en el panorama literario latinoamericano, voluntad de influir en el rumbo estético y 
político de una literatura, de marcar tendencias, de polemizar, de derrumbar cánones oficiales y de proponer cánones alternativos. Un tipo de intervención, además, que nace enmarcada en un gesto típicamente vanguardista en el cual se imponen estrategias panfletarias y de humor crítico antes que un tono reflexivo, académico o teórico. Este gesto es importante porque es el que se va a mantener con algunas variaciones en sus intervenciones críticas posteriores.

A la manera de los protagonistas de Los detectives salvajes (y a la manera de Rimbaud invocada por ellos), el Bolaño crítico también se pierde después de su corto pero intenso paso por el movimiento infrarrealista. Luego de algunos premios y publicaciones que no tuvieron gran repercusión, será a partir de $L a$ literatura nazi en América, Llamadas telefónicas, y definitivamente a partir de 1998 con Los detectives salvajes, que Bolaño reaparezca con fuerza en la escena de la literatura en lengua española. Y a su regreso como narrador consagrado le sigue nuevamente un corto pero intenso periodo de intervenciones críticas en diarios, revistas, ciclos de conferencias y debates que intentaré analizar a continuación.

\section{A partir de 1998, el escritor consagrado}

La mayor parte de las intervenciones críticas de Bolaño aparecieron después de 1998 y fueron reunidas por Ignacio Echevarría en el libro titulado Entre paréntesis, publicado de forma póstuma en 2004. Corresponden a este conjunto de intervenciones discursos, prólogos, notas y reseñas sobre literatura, escritos sobre viajes, presentaciones de libros y artículos sobre su propia práctica literaria. Además de estos textos críticos, he incorporado en el análisis el conjunto de entrevistas seleccionadas y publicadas por Andrés Braithwaite en 2006 con el título de Bolaño por símismo, entrevistas escogidas, así como los diálogos que Bolaño realizó con Rodrigo Fresán, Dos hombres en el castillo, publicado originalmente en la revista Letras Libres de Madrid en junio de 2002, y con Ricardo Piglia, Extranjeros del Cono Sur, publicado originalmente en el diario El País de Madrid, en marzo de 2003.

Como veíamos antes, estas intervenciones críticas se producen, en su gran mayoría, en los últimos cinco años de vida del escritor: el periodo comprendido entre el momento de su consagración, con la obtención del Premio Herralde y del Premio Rómulo Gallegos — dos de los principales premios literarios en lengua española- por Los detectives salvajes en 1998, y su muerte prematura en 2003.

El torbellino de la escritura bolañiana se manifiesta también en estos textos que parecen querer apropiárselo todo: lecturas de escritores y obras de todo tipo, clásicos, contemporáneos, latinoamericanos, europeos, norteamericanos, novelas policiacas, del oeste, comentarios sobre cine, sobre política, 
textos autobiográficos y sobre viajes, consejos para escribir cuentos y discursos sobre el exilio y la literatura latinoamericana.

Textos como las notas sobre literatura o los prólogos permiten pensar más directamente la cuestión del escritor como crítico o el escritor como lector, y muestran la manera particular en que un escritor se aproxima a otros textos ficcionales y cómo se va definiendo, por un lado, su idea de literatura y, relacionado con esto, su propio mito de escritor, algo que también aparece de manera evidente en sus entrevistas.

En relación con la forma de estos textos críticos bolañianos, es posible identificar en ellos varios "modos del ensayo", gestos y movimientos que los acercan a las particularidades del ensayo literario, entendido como búsqueda (Sarlo 18$)^{3}$ y como "ensayo de lecturas", es decir, aquella escritura crítica que toma la forma del recuerdo (Giordano 71). Varios recursos particulares usados comúnmente en el ensayo, como la polémica, la metáfora y el aforismo, hacen parte en mayor o menor medida de los textos críticos publicados por Bolaño, al mismo tiempo que muchos de ellos poseen la huella de otros géneros, como el autobiográfico.

Así como aprovechan algunos recursos y modos del ensayo y de lo autobiográfico, las intervenciones de Bolaño se caracterizan por tener un fuerte impulso descriptivo y narrativo. Bolaño habla de un escritor pero en realidad cuenta una historia: su propia historia, la historia del libro en cuestión, o una historia que le contó el escritor del que quiere hablar. En este sentido, sus notas pueden ser leídas también como ficciones, pequeños relatos que persiguen más un efecto estético que el desarrollo sistemático de una idea.

Es coherente con este argumento, como lo observa Echevarría, la propia intención de Bolaño de situar algunos textos — como las conferencias o discursos "Literatura + enfermedad = enfermedad" y "Los mitos de Chtulhu" - en un libro de cuentos, El gaucho insufrible, sin ninguna distinción o separación. Del mismo modo, algunos cuentos de Putas asesinas, como "Carnet de baile" y "Encuentros con Enrique Lihn", al igual que "Sabios de Sodoma", de su libro póstumo El secreto del mal, se sitúan en un lugar incierto entre el relato, la crítica y la autobiografía.

Los textos críticos de Bolaño se alejan de los de un lector profesional o académico. Son textos que se caracterizan por una fuerte presencia de la subjetividad del autor, razón por la cual es posible verlos en conjunto como una especie de "cartografía personal", como afirman Echavarría (7) y D'ors (197). Muchos de estos textos responden al afecto y transmiten experiencias de lectura, más que

3 "El ensayo escribe (y describe) una búsqueda [...] En el ensayo se dibuja un movimiento más que un lugar alcanzado" (Sarlo 18). 
resultados concretos o fines previamente determinados. No pretenden profundidad, ni se detienen demasiado en el detalle, como es posible observar en los ensayos de Borges, por ejemplo.

Algo que aparece de manera evidente en las intervenciones críticas de Bolaño es el carácter estratégico de sus textos construidos en permanente tensión por reorganizar un canon latinoamericano enloquecido, según él, a causa de las presiones del mercado y por rescatar del olvido a ciertos escritores, en su opinión, injustamente relegados. Sin embargo, aunque Bolaño escenifique de manera agresiva esa voluntad por imponer ciertos cánones y atacar otros, no considero que exista una gran excepcionalidad en sus apuestas canónicas. El canon propuesto por Bolaño coincide, quizás con pocas excepciones, con el canon comúnmente construido por la crítica académica y otros escritores en torno de la literatura latinoamericana en los últimos años.

Tal vez su particularidad sea el tono agresivo y sarcástico con el que descalifica autores identificados por él con la literatura comercial y con posturas sumisas al poder político, pero no se percibe en sus propuestas una gran renovación o cuestionamiento del canon establecido y de los estereotipos vigentes. Lo que sí existe es una intencionalidad por identificarse con ciertos autores que ya hacen parte de ese canon, como Borges, Cortázar, Bioy Casares y Nicanor Parra, y por incorporar su nombre a una familia de escritores contemporáneos que considera valiosos, como Sergio Pitol, Ricardo Piglia, César Aira, Carmen Boullosa, Rodrigo Rey Rosa y Fernando Vallejo.

Es común encontrar en sus reseñas y comentarios sobre otros autores y obras pistas sobre lo que es o debería ser su propia literatura. Cuando Bolaño escribe sobre Vila-Matas o sobre Vargas Llosa, para citar tan solo dos ejemplos significativos, los aspectos específicos que destaca de esos escritores - la mezcla de diversos géneros en Vila-Matas, la proliferación de voces en las obras de Vargas Llosa - aparecen también como posibles pistas para acercarse a su propia obra ficcional, o por lo menos, a lo que Bolaño aspiraba alcanzar en ella.

En sus intervenciones hay una tendencia a formar grupos de escritores y a establecer jerarquías que finalmente le permiten al propio autor construirse un espacio en el campo literario latinoamericano contemporáneo. En el caso de las clasificaciones bolañianas, los autores tienden a agruparse por características que se acercan más a una cierta posición ética del escritor, que por características formales de su literatura, como veíamos en el caso de las intervenciones críticas de la etapa infrarrealista. Lo que prima en las jerarquías de valor bolañianas parece ser una cierta postura "valiente" del escritor frente a la institución literaria, el poder político y el mercado, unida a un compromiso ético en la práctica literaria relacionado con la innovación formal, por un lado, y con 
"no cerrar los ojos ante el horror", por el otro; generalmente Bolaño se refiere con esto al horror de las dictaduras latinoamericanas, pero también a la violencia urbana y más ampliamente al "mal", uno de los temas que atraviesa toda su obra.

La intención de tratar la literatura americana en su conjunto -incluyendo Brasil, Norteamérica y las islas del Caribe no hispánico-, que Bolaño realiza en un texto ficcional como La literatura nazi en América, no se repite en sus intervenciones críticas. Especialmente se percibe en Bolaño la ausencia casi total de referencias a la literatura brasileña, una constante histórica por parte de los escritores hispanoamericanos (a pesar de algunas excepciones). Aparte de ciertos comentarios negativos contra Nélida Piñón y Paulo Coelho (símbolo del escritor best-seller contra el que se enfrenta Bolaño en sus intervenciones), no hay referencias a la literatura brasileña en sus textos críticos. En este sentido, sería más exacto hablar del canon literario hispanoamericano; pese a que Bolaño siempre se refiera a Latinoamérica, es este canon el que tiene en mente cada vez que realiza sus intervenciones críticas.

A partir del momento de su consagración, las intervenciones críticas de Bolaño comienzan a aparecer en diarios y revistas de España y de América Latina y el escritor empieza a ser invitado para dar charlas y discursos en diferentes eventos literarios, académicos y culturales. La mayor parte de sus notas y reseñas sobre literatura, las que escribió de manera más sistemática, fueron inicialmente publicadas en el Diari de Girona (donde eran traducidas al catalán) y aparecían en una columna al lado del editorial del diario. La mayoría de estas mismas columnas, con ciertos cambios menores, y algunas otras nuevas fueron después publicadas en el diario chileno Las Últimas Noticias.

Otras notas, artículos y entrevistas fueron publicados en suplementos literarios de diarios españoles como El Mundo y El País, argentinos como Clarín y Página 12, chilenos como El Mercurio y El Metropolitano y mexicanos como Reforma y Unomásuno, y ven revistas culturales de Barcelona como Lateral y Ajoblanco, la revista Turia de Teruel y la revista chilena Paula. La última entrevista de Bolaño fue publicada en la edición mexicana de Playboy en julio de 2003. Otras entrevistas aparecieron en periódicos y revistas, impresas y digitales, de Caracas, Bogotá, Córdoba, Turín, Montpellier y La Paz. Así mismo, Bolaño fue entrevistado en radio (Radio Francia Internacional en mayo de 2002) y en televisión (en el programa Off the record de la Universidad Católica de Valparaíso y en el programa La belleza de pensar del canal por cable 13 de Chile durante su visita al país en diciembre de 1999) ${ }^{4}$.

4 Un amplio listado con la procedencia de los textos críticos de Bolaño se encuentra en Entre paréntesis (345-355). Puede consultarse una lista con la procedencia de sus entrevistas en Braithwaite (127-130). 
He separado en tres grandes bloques estas intervenciones para analizar con mayor detalle algunas de sus principales características. Estos bloques son los discursos, las notas sobre literatura y las entrevistas. En cada uno de ellos predomina, aunque no sea de manera exclusiva, un cierto modo particular de la escritura de Bolaño: el panfletario es más común encontrarlo en el caso de los discursos, el autobiográfico en el de las notas sobre literatura y el de la construcción de su imagen como escritor en el caso de las entrevistas.

\section{Los discursos o el neopanfleto literario}

En un comentario que le envía por correo electrónico a su amigo Ignacio Echevarría en relación con un artículo que acababa de publicar en el diario chileno Las Últimas Noticias, titulado "Sobre la literatura, el Premio Nacional de Literatura y los raros consuelos del oficio", Bolaño dice: "Querido Ignacio: Restif de la Bretonne en las barricadas o cómo seguir haciendo amigos en Chile. El neopanfleto será el gran género literario del siglo XXII. En este sentido, soy un autor menor, pero adelantado" (Entre paréntesis 349). Podemos entender los discursos de Bolaño como una especie de panfletos literarios en el sentido de textos que, más que realizar análisis sobre un determinado autor, obra o tradición literaria, se presentan como misivas polémicas donde un autor expresa de manera frontal y agresiva sus opiniones en favor y en contra de determinados autores y tipos de literatura.

Los textos panfletarios de Bolaño buscan seguidores o contendores y no pretenden analizar a profundidad ningún fenómeno, estético o político. Se trata de evidenciar de manera frontal sus puntos de vista y gustos literarios sin consideraciones con ningún tipo de cortesía o diplomacia literaria.

Bolaño no interviene como investigador o crítico literario, en el sentido convencional y académico del término. El gesto de Bolaño en sus discursos es el gesto de un provocador y un polemista que emite tajantes juicios de valor para llamar la atención sobre determinados autores o para atacar a otros de forma agresiva y demoledora.

El panfletario generalmente se presenta como un marginal porque él mismo se excluye del sistema institucional, como un solitario dotado de coraje intelectual y lleno de indignación. Pero ¿contra qué se rebela Bolaño, cuál es el objeto de su indignación, de qué quiere convencernos?

A partir de algunos de estos textos podemos identificar sus principales objetos de ataque: por un lado, los escritores que venden (ya veremos este punto con más cuidado) y por el otro, los escritores que se rinden ante cualquier forma de poder político establecido. 
Como veíamos antes, desde sus primeros textos críticos Bolaño actualiza el gesto vanguardista identificando, de una parte, el aparato oficial de la literatura y, de otra, un movimiento marginal identificado con la "verdadera" literatura. En este segundo momento de sus intervenciones, el ataque de Bolaño parece encaminarse principalmente hacia los autores de éxito de mercado (Coelho, Pérez Reverte, Isabel Allende, etc.), a los que se opone una tradición de "verdaderos" escritores (Borges, Cortázar, Wilcock, Fernando Vallejo, Sergio Pitol).

El peso de las intervenciones bolañianas recae sobre la figura del escritor y del poeta, más que en sus obras específicas. Parece como si la vida del escritor y un cierto compromiso ético fueran determinantes para juzgar la calidad de una obra.

Aquí el compromiso ético no tiene que ver necesariamente con una cierta concepción del bien y del mal. Bolaño afirma en varias ocasiones que el escritor puede ser un infame y aun así escribir grandes obras literarias (precisamente la relación entre belleza y perversión es uno de sus temas preferidos). El compromiso ético al que se refiere Bolaño tiene que ver principalmente con una actitud ante la página en blanco: la innovación formal. Aunque se pueda cuestionar, como en efecto ha ocurrido, que la obra de Bolaño sea de una gran innovación formal, este es un criterio que él juzgaba central para valorar la calidad de una obra literaria, más allá de haberlo conseguido siempre en sus propios textos.

Una de las cuestiones centrales de los panfletos bolañianos es la lucha entre la "buena" y la "mala" literatura. Pareciera como si Bolaño y junto a él otros autores como Pitol o Vila-Matas, por ejemplo, que también evidencian en sus escritos esa lucha por "salvar" la literatura (lo que para ellos es la "verdadera" literatura) estuvieran en un punto de quiebre, un lugar de giro: de un lado, la literatura que ellos quieren y defienden y que ellos mismos "hacen"; de otro lado, algo que no es literatura y que hay que combatir: mala literatura, literatura que vende, literatura que se entiende, falsa literatura (los nombres son variados). Aunque parece difícil llegar a un consenso sobre la definición de lo que sería "mala literatura", hay un aspecto que se repite en varios textos y discursos de Bolaño: es literatura que vende.

Siguiendo una idea del poeta catalán Pere Gimferrer, a quien cita en varias ocasiones en sus intervenciones críticas, Bolaño plantea que ahora los escritores, especialmente en Latinoamérica, estarían buscando respetabilidad. Al no salir de las clases altas y de la aristocracia como antes, donde el escritor buscaba principalmente el escándalo social, la destrucción de los valores o la crítica permanente, sino de la clase media y el proletariado, lo que busca ahora el escritor es respetabilidad, reconocimiento del poder político y reconocimiento del público, y esto se mide a través de la venta de sus libros. "Algunos utilizan más el cuerpo, 
otros utilizan más el alma, pero a fin de cuentas de lo que se trata es de vender", dice Bolaño en uno de sus discursos:

¿Qué no vende? Ah, eso es importante tenerlo en cuenta. La ruptura no vende. Una escritura que se sumerja con los ojos abiertos no vende. Por ejemplo: Macedonio Fernández no vende. Si Macedonio es uno de los tres maestros que tuvo Borges (y Borges es o debería ser el centro de nuestro canon) es lo de menos. Todo parece indicarnos que deberíamos leerlo, pero Macedonio no vende, así que ignorémoslo. Si Lamborghini no vende, se acabó Lamborghini. Wilcock solo es conocido en Argentina y únicamente por unos pocos felices lectores. Ignoremos, por lo tanto, a Wilcock. (Entre paréntesis 312)

A pesar de que el mismo Bolaño se apresure a negarlo, "era broma. Lo escribí, lo dije sin querer", dice más adelante en su discurso, esta es una idea que se repite en muchos de sus textos críticos, discursos y en su obra misma.

No deja de ser un tanto paradójico el hecho de que Bolaño se haya convertido en los últimos años relativamente en un escritor de éxito de ventas, no a un nivel de best-sellers como Paulo Coelho o Pérez-Reverte, pero sí con una aceptación de mercado más alta que la de muchos de sus contemporáneos. Quizás la escritura de Bolaño no se aleja tanto, como tal vez él mismo quisiera y como admiraba en otros escritores, de las expectativas del mercado, lo cual, unido a su muerte prematura, al boom publicitario sobre su figura de escritor outsider y a la calidad de su obra, le ha permitido ocupar lugares destacados en el campo literario contemporáneo tanto en términos de ventas de sus libros como de los juicios valorativos de la crítica especializada.

¿Qué buscaba Bolaño con la actitud agresiva y polémica de sus discursos? ${ }_{\mathrm{C}}$ Por qué ahora, en una época en la que asistimos a una cierta predominancia de relativismo estético, Bolaño intenta revivir el juicio valorativo y agresivo de lo literario, de lo que es "buena" o "mala" literatura? Varias respuestas son posibles. Si pensamos en la figura del escritor en cuanto crítico como la de un estratega en el combate literario, podemos entender este tipo de intervenciones como una apuesta agresiva por establecer su propia posición en el campo. Bolaño lanza sus ataques contra una literatura de mercado o sumisa, que para él ha ocupado el lugar que le corresponde a la "verdadera" literatura. Y mediante esa defensa es claro que también defiende su propio lugar, el lugar de su propia obra, que antes de su consagración y de su muerte prematura tenía poca visibilidad. Su visión obsesiva de la literatura entendida como un oficio peligroso es asimismo llevada a la práctica en sus intervenciones críticas, por lo que aparece como el defensor de la "buena" literatura. 
Por otro lado, ese gesto se relaciona con el espíritu polémico y contestatario de Bolaño, por lo menos con la figura de escritor que él mismo contribuyó a construir. Tanto en sus entrevistas como en detalles biográficos que revela en algunos de sus textos, Bolaño solía destacar ese afán contestatario como una de las características más marcadas de su personalidad. "La unanimidad me jode muchísimo", dice; "cuando veo que todo el mundo está de acuerdo en algo, cuando veo que todo el mundo anatematiza algo a coro, hay algo a flor de piel que me hace rechazarlo" (Braithwaite 37).

En un ambiente literario dominado mayoritariamente por la figura del escritor-crítico-académico, o por el escritor-de-éxito comercial (best-seller), Bolaño intenta revivir la figura del vanguardista, el escritor-excéntrico que busca chocar con su discurso y su postura vital, agresiva e irreverente. Aunque la efectividad de esa estrategia sea relativa en el contexto contemporáneo, donde el gesto transgresivo parece ser rápidamente apropiado por el mercado, creo que la actitud irreverente de Bolaño contribuyó a sacudir un poco el campo literario latinoamericano de los últimos años. Más allá de imponer o no su propia visión de la literatura, el polemista consigue su objetivo: el público no puede quedarse indiferente.

\section{Las notas sobre literatura o la autobiografía del escritor como lector}

Contrario al Bolaño polémico y agresivo que aparece en sus discursos, Bolaño completamente diferente, generoso - algunas veces demasiado generoso- y amigable, aparece en sus notas sobre literatura. Textos que a veces veo como anotaciones sueltas en un diario de escritor/lector, o como pequeños ejercicios de escritura realizados en los momentos en que el escritor se aparta de su novela o de sus cuentos o poemas.

Son textos donde el escritor quisiera compartir con nosotros una experiencia placentera, como cuando un amigo nos recomienda un libro o una película que le ha gustado. "Toma, lee esto", parece decir Bolaño, "es uno de los mejores libros que he leído en mi vida". Ese tipo de afirmaciones perentorias es frecuente en sus notas sobre literatura, afirmaciones que no obedecen a un juicio crítico elaborado sino a un impulso y a un afecto, a una experiencia de lectura que quiere ser transmitida y compartida de inmediato.

Estas notas parecen el testimonio público de un placer de lector. Al igual que Borges, el escritor que más admira, Bolaño repite con frecuencia que es más feliz leyendo que escribiendo y estas notas dan la impresión de querer transmitir algo de esa experiencia feliz de lectura. 
Las notas de Bolaño son variadas y en muchas ocasiones responden a una solicitud específica: una reseña, la presentación de un libro, un prólogo para una colección. Los temas son mayoritariamente literarios: escribe sobre libros y autores de las más diversas tradiciones y épocas (aunque cuantitativamente se impongan escritores contemporáneos y de América Latina) o sobre aspectos específicos de la literatura chilena y latinoamericana. Pero también hay notas de viajes y lugares y algunos textos sobre temas políticos.

Concuerdo con D'ors en que las notas de Bolaño, que él insiste en definir como ensayos a pesar de decir que Bolaño no era un ensayista, "son un homenaje continuo a los escritores que admira" (D'ors 198). Muchos de esos escritores son también sus amigos personales, como en el caso de Rodrigo Fresán, Mario Santiago o Juan Villoro. Pero no solo en función de la amistad que lo une a ciertos escritores Bolaño realiza sus comentarios elogiosos. Así como suele ser un crítico demoledor con los escritores que no son de su simpatía, de la misma manera es increíblemente generoso con los escritores que le gustan. Bolaño suele usar frases como "La sinagoga de los iconoclastas [de J. Rodolfo Wilcock] es uno de los mejores libros que se han escrito en este siglo" (Entre paréntesis 281) o "Aira es un excéntrico, pero también es uno de los tres o cuatro mejores escritores de hoy en lengua española" (Entre paréntesis 137$)^{5}$.

A través de esas notas, muchas veces terminamos sabiendo más sobre el propio Bolaño, sobre su formación, sobre sus gustos, que sobre el autor o la obra en cuestión. Precisamente, también es posible observar en sus intervenciones críticas un cierto carácter autobiográfico que permea su escritura ficcional, aunque no se trate de la autobiografía tradicional, como se verá más adelante. A pesar de que Bolaño mostró siempre cierto recelo sobre el género autobiográfico como tal, al que consideraba solo digno de ser ejercido por personalidades "singulares" (Entre paréntesis 28), la huella autobiográfica se filtra en toda su obra, incluyendo sus notas e intervenciones.

A través de estos textos podemos trazar un mapa de las lecturas de formación del escritor. No solo de lo que lee en el momento en que escribe sus notas, sino también de sus lecturas de juventud, de los libros que robaba, de los que marcaron su vida y que posiblemente influenciaron su propia práctica ficcional. Libros como La caída de Camus y más tarde la Obra gruesa y Artefactos de Nicanor Parra, así como los de poesía de Enrique Lihn y de Jorge Teillier. A través de esas pistas es posible rastrear algunas influencias: el impacto positivo que le

5 Su posición positiva respecto a Aira cambiaría unos años después. En su discurso "Derivas de la pesada", juzgaría la mayor parte de su obra como "acrítica" y "aburrida". 
produjo La sinagoga de los iconoclastas de Wilcock, por ejemplo, que Bolaño relacionaba en sus notas con antecedentes famosos como las Vidas imaginarias de Schwob, los Retratos reales e imaginarios de Alfonso Reyes y la Historia universal de la infamia de Borges, está detrás de la construcción de una novela como La literatura nazi en América. Su preferencia por la épica y la insistencia en el valor y la valentía pueden relacionarse con la influencia decisiva de la obra de Borges, así como el humor y la irreverencia de su postura, con las lecturas de Nicanor Parra, Julio Cortázar o Augusto Monterroso.

A través de sus notas es posible identificar a los autores que más admira Bolaño. Entre los principales podemos citar a Phillip K. Dick, Burroughs, Borges, Cortázar, Mark Twain y Nicanor Parra, diversas influencias y tradiciones que se mezclan en su propia obra ficcional. En este sentido, no parece arriesgado pensar que gran parte de la obra de Bolaño se caracteriza por una mezcla singular de una tradición vitalista y de aventuras (tipo beatnik) y una tradición más metaliteraria como la de Borges y, en parte, Cortázar. La propuesta de Bolaño sería la siguiente: en vez de escribir sobre libros y lecturas — aunque también lo haga-, escribir sobre la vida peligrosa de los poetas, sobre la cercanía de la literatura con el mal y lo perverso.

$\mathrm{Al}$ igual que en algunos de sus discursos, también en las notas hay un impulso narrativo muy fuerte que desplaza la interrogación o la inquisición propia del ensayo hacia la descripción y la narración, o incluso la poesía - muchos de sus textos suelen terminar con frases que bien podrían haber hecho parte de uno de sus poemas narrativos- Tal vez por esa razón estas notas se acerquen más al artículo y a la crónica que al ensayo propiamente dicho, aunque, como en el ensayo, dejen el camino abierto para nuevas incursiones en el tema.

Generalmente la estructura de estas notas sobre literatura se construye con los mismos elementos: un detalle autobiográfico sobre el momento en que Bolaño leyó el libro acerca del que quiere hablar; una breve referencia a los datos biográficos y bibliográficos del autor, cuando este no es tan conocido; un resumen del argumento de la novela o la descripción del personaje central; algunas frases cortas para definir el estilo del autor o la obra en su conjunto; y el concepto de Bolaño, casi siempre favorable y categórico, sobre la obra y el autor.

El tono predominante en estos textos, como lo anota D'ors es el tono digresivo e informal (198-20o). Bolaño pasa de un tema a otro con facilidad, recuerda un sueño, cuenta una anécdota y luego vuelve al tema central, dando vueltas y desviándose continuamente. Con frecuencia se detiene más en estas digresiones que en el propio tema que se había propuesto discutir. Algunas veces el tema es solo una excusa para contar una historia, como en la nota dedicada al escritor 
Rodrigo Rey Rosa (Bolaño, Entre paréntesis 199-200). Bolaño dice en el primer párrafo que sería conveniente hablar de sus últimos libros, pero después de clasificarlo como "el escritor más riguroso de mi generación", prefiere contar una historia que Rosa le contó a él. A partir de ese momento, el texto se convierte en un pequeño relato de la aventura de Rey Rosa en Mali.

También, como en la mayor parte de su ficción, predomina en las notas de Bolaño el tono conjetural. Abundan los adverbios: "tal vez", "quizás", y frases que comienzan con "si mal no recuerdo", "creo que fue así, pero pudo ser de otro modo". Así mismo, hay ciertos olvidos - un nombre, una fecha exactao displicencias que el autor se permite - como no consultar de nuevo un libro sobre el que está hablando en ese momento-. Ese tono conjetural contrasta con sus afirmaciones categóricas pero no las anula; al contrario, parece jugar con la credibilidad del lector, que tiende a confiar más en un autor-narrador que aparentemente está siendo "sincero".

A pesar de un cierto tono grandilocuente que recorre sus notas sobre literatura, Bolaño conserva el humor y la ironía que caracteriza sus discursos y del cual hace gala en sus entrevistas. Vistas en conjunto, el movimiento entre las afirmaciones categóricas y definitivas, el tono conjetural y la ironía que recorren estas notas hacen dudar sobre la seriedad y coherencia de las ideas que Bolaño expone. La sensación final no es del todo clara. ¿Está bromeando? A veces parece que sí, otras veces no. ¿ Realmente Bolaño cree en todo lo que dice o se trata de una permanente provocación?

\section{Las entrevistas o la construcción del mito personal del escritor}

Algunos ejemplos de la recepción de Bolaño en los Estados Unidos pueden servir para ilustrar los andamiajes, equívocos y deseos que se ocultan tras las construcciones de mitos. Tanto la reseña de Los detectives salvajes del New Yorker en 2007 como la elogiosa reseña de 2666, escrita por Jonathan Lethem, en The New York Times Book Review en noviembre de 2008, y las reseñas de 2666 y Los perros románticos de Sarah Kerr en el mismo diario un mes después, contribuyeron a la construcción del mito de Bolaño como escritor maldito, atribuyendo incluso su enfermedad crónica al uso de heroína, algo que ha sido desmentido por personas cercanas a Bolaño ${ }^{6}$.

6 Amigos del escritor como Bruno Montané, Antoni García Porta e Ignacio Echavarría se pronunciaron contra esta información en el Periódico de Barcelona en noviembre de 2008. En una carta de enero de 2009, Sarah Kerr pidió disculpas, afirmando que había simplemente seguido la información de segunda mano publicada anteriormente sobre Bolaño en los Estados Unidos. 
El equívoco puede obedecer no solamente a una intención determinada por cierto tipo de recepción - que, por otro lado, no es exclusiva de los Estados Unidos - sino a la lectura sin matices del propio mito personal del escritor que Bolaño elabora tanto en sus intervenciones críticas como en su obra narrativa y poética a través de la figura de sus narradores y personajes con rasgos autobiográficos: Arturo Belano, B., Bolaño, etc.

En este caso la suposición de la adicción a la heroína pudo haber sido extraída de una crónica que Bolaño escribió para el diario El Mundo de Madrid en agosto del año 2000, titulada "Playa", donde relata en primera persona la historia de un exconsumidor.

Con relación a su vida, como afirma Villoro, Bolaño "rara vez rehuyó hablar de temas personales, pero no le interesaba la literatura confesional, sino la autofabulación" (11). De ahí que sea común que los lectores, incluso los más avisados, suelan caer en la confusión entre vida real y autofabulación, atribuyendo al Roberto Bolaño biográfico hechos y características del Bolaño escritor-personaje. Precisamente ese juego con las fronteras entre la ficción y la autobiografía aparece como una de las estrategias centrales en su obra.

Pero ¿cuáles son las características de ese mito personal del escritor que Bolaño elabora? La imagen que Bolaño construye de sí mismo es la imagen de un escritor irreverente, polémico, rebelde, valiente, inteligente, solitario, irónico, que vivió intensamente su vida y que parece haberlo leído todo. El carácter contradictorio y polémico de muchos de sus artículos, discursos y notas sobre literatura, así como las respuestas provocadoras que suele dar en sus entrevistas, contribuyen a crear la imagen del "escritor-rebelde" más preocupado por desafiar un cierto estado de cosas que por elaborar un pensamiento crítico coherente y profundo sobre la literatura o el campo literario (lo que no quiere decir que Bolaño no tuviera un conocimiento especializado en literatura).

La figura que Bolaño construye de sí mismo le debe mucho a ese espíritu vanguardista inicial, a su visión de la literatura como un combate y a la importancia que Bolaño le atribuye a la fusión vida-obra. En este sentido, es evidente, aunque muchas veces aparezca de forma velada, su intención de destacar los aspectos de su biografía que más se ajustan a la figura del escritor outsider y no a la del escritor-intelectual o profesional.

Aunque a veces Bolaño parece restarle importancia en sus entrevistas a su vida errante, o a su breve experiencia en la resistencia y su estadía en prisión durante los primeros días de la dictadura militar chilena, por ejemplo, constantemente desliza algunos detalles particulares para establecer su diferencia con cierto tipo de escritor-intelectual o escritor aliado con el poder político o 
económico dominante, ubicándose siempre al margen del sistema. Bolaño se ve a sí mismo, y es la imagen que nos quiere transmitir, como un valeroso guerrero solitario que se enfrenta a todos y a todo con la única arma de su escritura y su compromiso radical con la literatura.

Por otro lado, en las entrevistas Bolaño se presenta como un gran conocedor de la tradición literaria y respetuoso de los escritores que admira. En ese sentido se diferencia el Bolaño maduro del gesto vanguardista inicial que tiende a borrar de un solo golpe gran parte de la tradición literaria precedente para instaurar un nuevo orden.

La ironía y el humor son otros trazos decisivos de la figura de escritor que Bolaño va construyendo a través de sus entrevistas. Humor e ironía que funcionan muchas veces como un contrapunto para su visión melancólica y desilusionada. Así como en su obra ficcional, el humor aparece como una postura vital para enfrentar el sinsentido de la existencia.

Como veíamos antes, su humor más sarcástico y punzante aparece en sus discursos, conferencias y entrevistas, donde Bolaño se muestra como un polemista literario radical, sin hacer concesiones de ningún tipo. Son famosos sus comentarios mordaces contra figuras canónicas de la literatura latinoamericana como García Márquez, Vargas Llosa, Octavio Paz y Neruda.

La figura que Bolaño elabora de sí mismo es un contrapunto a la imagen de escritor-intelectual-comprometido herencia del boom, pero también a la imagen del escritor contemporáneo de éxito de mercado. Para hacerlo, Bolaño recupera el espíritu beligerante de las vanguardias y el mito romántico del escritor en lucha permanente contra el mundo. La imagen del escritor que no cede ante las tentaciones del poder político y económico y que nunca se incorpora del todo al sistema literario.

Sin embargo, la figura que construye Bolaño (voluntaria o involuntariamente) es ambigua en cuanto a las relaciones entre literatura y política. En algunas ocasiones, su postura no se aleja tanto del carácter del escritor-intelectual-político comprometido del pasado, algo que se evidencia en muchos de sus artículos, discursos y entrevistas y en su propia actitud performática de intervención pública. Pero, al mismo tiempo, Bolaño también defiende con frecuencia la separación de las esferas (literatura y política), reafirmando que el compromiso del escritor debe juzgarse solamente en relación con su propia práctica literaria y artística, independientemente de sus posturas y compromisos éticos y políticos individuales: "El único deber de los escritores", afirma Bolaño en otra entrevista, "es escribir bien y, si puede ser, algo mejor que bien; intentar la excelencia. Después como individuos que hagan lo que quieran; a mí eso me importa poco. Que sean 
coleccionistas de latas de cerveza o aficionados al fútbol, perritos falderos de la primera dama o heroinómanos" (Braithwaite 26).

Afirmaciones como esta muestran también las contradicciones del pensamiento bolañiano, pues precisamente es la fusión obra-vida uno de los criterios centrales que el propio Bolaño utiliza para juzgar el valor de una obra literaria. En todo caso, me parece que Bolaño contribuye con sus intervenciones, a través del efecto de indeterminación que producen la ironía, el juego con las fronteras de los géneros y la desestabilización de los discursos, a problematizar las concepciones rígidas - en literatura, en política- y las verdades absolutas. La contradicción, la conjetura, la broma son armas del escritor contra el pensamiento único, el conformismo y la apatía. Tal vez habría que buscar allí y no en declaraciones puntuales del escritor (que suelen ser ambiguas y contradictorias) el aporte político de las intervenciones bolañianas.

Por otro lado, Bolaño siempre se presentó como un escritor latinoamericano, transnacional, sin claras raíces en un único país. Le gustaba jugar con la idea de que era reconocido como español por los chilenos, chileno por los mexicanos y mexicano por los españoles. Esta transnacionalidad es frecuente también encontrarla en sus textos ficcionales, en la diversidad de sus geografías, las procedencias de los personajes, los acentos y expresiones de diversas regiones del mundo (aunque mayoritariamente de América Latina).

En este sentido, no es fácil ubicar a Bolaño en una sola tradición nacional: chilena, mexicana o argentina. Algunos estudios críticos recientes, como el Diccionario de escritores mexicanos (2007) de Christoper Domínguez Michael, incluyen a Bolaño en la tradición literaria mexicana. Pero tampoco parece descabellado ubicarlo en una línea de tradición argentina post-Borges, metaliteraria, en diálogo, por ejemplo, con la literatura de Piglia. Inclusive, creo que hay alguna intención de su parte por dialogar en forma permanente con la literatura española, tanto con los autores canónicos como con los contemporáneos a quienes les dedica un espacio considerable en sus notas y reseñas.

Una de las características centrales que he venido resaltando en estas páginas se observa igualmente en las entrevistas que Bolaño concedió - casi todas ellas respondidas por escrito- y contribuye a afianzar su imagen de escritor total, de enfermo de literatura. Me refiero a que también en sus entrevistas aparece claramente el deseo de hacer literatura. Algunas respuestas de Bolaño parecen ficciones, prosa literaria o poemas, como ya lo destacaba Juan Villoro (11). Al ser preguntado en una entrevista por la persona o cosa en que le gustaría volver a la tierra después de morir, Bolaño responde: "Un colibrí, que es el más pequeño de los pájaros y cuyo peso, en ocasiones, no llega a los 
dos gramos. La mesa de un escritor suizo. Un reptil del desierto de sonora" (Braithwaite 46).

De igual manera, antes que revelar aspectos concretos de su biografía, lo que aparece en las respuestas de Bolaño relacionadas con su vida personal son autofabulaciones, pequeñas historias donde sucesos reales se convierten en ficciones o se mezclan con recuerdos de lectura o con sueños.

De esta forma, desestabilizando todo el tiempo las fronteras entre lo real y lo ficcional, jugando con los límites entre géneros críticos y ficcionales, Bolaño contribuyó a crear su propio mito. Tanto es así que continúa siendo difícil separar la figura del Bolaño-escritor-personaje de la del Bolaño-biográfico, lo que me lleva a pensar que tal vez Bolaño consiguió lo que quería y que, por lo menos por ahora, continuará imponiéndose la figura del mito romántico que construyó a lo largo de su vida y en la que quizás él mismo se perdió (o se encontró) como quería.

\section{Obras citadas}

Bolaño, Roberto. "Déjenlo todo, nuevamente. Primer manifiesto del movimiento infrarrealista". 1977. Web. 8 de diciembre de 2013.

-. Entre paréntesis. Barcelona: Anagrama, 2004.

—. "El estridentismo". Revista Plural 61 (noviembre de 1976): 48-50.

-. org. Muchachos desnudos bajo el arcoiris de fuego, once jóvenes poetas latinoamericanos. México: Extemporáneos, 1979.

-. "La nueva poesía latinoamericana (crisis o renacimiento)". Revista Plural 68 (mayo de 1977): 42-43.

-. "Tres estridentistas". Revista Plural 62 (noviembre de 1976): 47-60.

Braithwaite, Andrés, selección y edición. Bolaño por sí mismo, entrevistas escogidas. Santiago: Universidad Diego Portales, 2006.

Campos, Javier. "Bolaño y los poetas infrarrealistas". 2004. Web. 27 de julio de 2009.

Cobas Carral, Andrea. "'Déjenlo todo nuevamente': apuntes sobre el movimiento infrarrealista mexicano". 2005. Web. 27 de julio de 2009.

Domínguez-Michael, Christopher. Diccionario crítico de la literatura mexicana (1955-2005). México: FCE, 2007.

D'ors, Pablo. "Los ensayos de un narrador". Revista Cultural Turia 75 (junio-octubre de 2005): 194-202.

Echevarría, Ignacio. Presentación a Entre paréntesis. Por Roberto Bolaño. Barcelona: Anagrama, 2004. 7-16.

Espinosa, Patricia. "Bolaño y el manifiesto infrarrealista". Rocinante 84 (octubre de 2005). Web. 28 de julio de 2009. 
García Huidobro, Cecilia. "Bolaño, el estridentismo y Cesárea Tinajero o cómo hacer una literatura con sombra". Conferencia Universidad de Salamanca, De Huidobro a Bolaño: un siglo de vanguardias chilenas en España, 3-4 de junio de 2008.

Giordano, Alberto. "Imágenes de José Bianco ensayista". Boletín 9, Centro de Estudios de Teoría y Crítica Literaria (diciembre de 2001): 53-76.

Longoni, Ana. "La teoría de la vanguardia como corset".

Pensamiento de los Confines 18 (2006): 61-68.

Sarlo, Beatriz. "Del otro lado del horizonte". Boletín 9, Centro de

Estudios de Teoría y Crítica Literaria (diciembre de 2001): 16-31.

Schwartz, Jorge. Vanguarda e cosmopolitismo. São Paulo: Perspectiva, 1983.

Villoro, Juan. "La batalla futura". Braithwaite 9-20. 